\title{
Um réquiem para Clovis
}

\section{A requiem for Clovis}

\author{
Adriana Schmidt Dias (D) \\ Universidade Federal do Rio Grande do Sul. Porto Alegre, Rio Grande do Sul, Brasil
}

\begin{abstract}
Resumo: No início do século XXI, o tema povoamento inicial da América ainda é sinônimo de controvérsia. Para além da diversidade de interpretações sobre os contextos arqueológicos com datações pleistocênicas, as divergências sobre a origem dos povos ameríndios recebem influências das diferentes lógicas que afetam a prática da arqueologia nas Américas, reforçadas pelos eventos científicos e por revistas acadêmicas. Essas questões serão analisadas aqui a partir de minha experiência como participante da conferência Paleoamerican Odyssey, que ocorreu em 2013 em Santa Fé, no Novo México (EUA).
\end{abstract}

Palavras-chave: História da Arqueologia. Povoamento da América. Modelo Clovis.

\begin{abstract}
At the beginning of the twenty-first century, the subject of the first settlement in the Americas still remains controversial. In addition to the varied interpretations of the archaeological contexts with Pleistocene dates, divergences on the origin of Amerindian peoples are influenced by the different logics that affect the practice of archeology in the Americas, reinforced in scientific events and academic journals. These issues will be analyzed here based on my experience as a participant in the Paleoamerican Odyssey Conference that took place in 2013 in Santa Fe, New Mexico (USA).
\end{abstract}

Keywords: History of Archeology. Settlement of the Americas. Clovis Model.

DIAS, Adriana Schmidt. Um réquiem para Clovis. Boletim do Museu Paraense Emílio Goeldi. Ciências Humanas, Belém, v. 14, n. 2, p. 459-476, maio-ago. 2019. DOI: http://dx.doi.org/10.1590/1981.81222019000200010.

Autora para correspondência: Adriana Schmidt Dias. Universidade Federal do Rio Grande do Sul. Campus do Vale. Avenida Bento Gonçalves, 9500. Porto Alegre, RS, Brasil. CEP 90035-141 (adrianasd96@gmail.com).

Recebido em 10/09/2018

Aprovado em 31/01/2019

(c) (i)

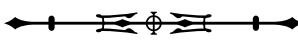




\section{UMA INTRODUÇÃO ÀS CONTROVÉRSIAS SOBRE O POVOAMENTO DA AMÉRICA (OU POR QUE VELHOS HÁBITOS SÃO DIFÍCEIS DE MATAR)}

Logo que as primeiras evidências sobre uma antiguidade pleistocênica para a presença humana no Velho Mundo começaram a surgir, iniciou-se a busca por testemunhos similares na América do Norte. A maioria dos 'paleolíticos americanos' provinha de depósitos geológicos com estratigrafia complexa, e a aceitação da sua antiguidade baseava-se na credibilidade do autor. Isso deu origem, na década de 1870, à prática da visita de especialistas aos sítios arqueológicos em disputa, onde críticos e proponentes examinavam as evidências in situ. A validade dos achados começou a ser questionada por William Henry Holmes, do Bureau of American Ethnology (BAE), e o que era, a princípio, uma discordância de opiniões, evoluiu a partir de 1890, para uma controvérsia que permaneceu sem solução até a descoberta do sítio Folsom, em 1927. Porém, mais do que questões sobre o fazer arqueológico, a controvérsia sobre o paleolítico americano implicava variadas disputas acadêmicas pelas fronteiras disciplinares, acirrando as diferenças entre profissionais e amadores e entre as instituições científicas da costa leste e oeste. A 'grande guerra paleolítica', que passou a ser travada nas trincheiras das escavações arqueológicas e nos salóes das reuniões científicas, criou, na nascente arqueologia norte-americana, uma atmosfera de suspeita entre defensores e críticos da antiguidade humana no continente, ao mesmo tempo em que oferecia o suporte ideológico perfeito para as guerras de extermínio dos povos indígenas que estavam sendo travadas naquele mesmo momento no oeste (Meltzer, 2015).

Quando Jesse Figgins e Harold Cook, do Museu de História Natural de Denver (Colorado), encontraram, em um sítio paleontológico próximo da cidade de Folsom (Novo México), pontas de projétil líticas, com características inéditas nas coleções etnográficas (fluted points), associadas às costelas de uma espécie extinta de bisão, comunicaram imediatamente as descobertas ao Bureau of American
Ethnology (BAE). Alěs Hrdlička, paleoantropólogo do BAE, recomendou que os achados fossem preservados in situ para avaliação de sua autenticidade e em agosto de 1927 especialistas das mais prestigiosas instituições do leste visitaram o sítio: o paleontólogo Barnum Brown (American Museum of Natural History) e os arqueólogos Alfred Kidder (Carnagie Institution) e Frank Roberts (Smithsonian Institution) (Meltzer, 2009). A divulgação oficial de Folsom ocorreu naquele mesmo ano no Encontro da American Association for the Advance of Science, em um simpósio intitulado Early Man in America, do qual participou a elite intelectual do momento (e para o qual Figgins e Cook não foram convidados). Finalmente, a presença pleistocênica dos humanos na América perdeu seu caráter hipotético naqueles dias préradiocarbono, passando-se a estimar o início da ocupação do continente entre 20.000 e 15.000 anos AP. Folsom transformou-se no tópico central de diversos eventos e publicações ao longo da próxima década, estimulando uma nova geração de pesquisadores a estudar um tema até então considerado um tabu (Meltzer, 2009).

Nos anos 1930, as escavações do sítio Clovis representavam a enorme mudança do fazer arqueológico nos EUA sobre o impacto do histórico-culturalismo. $O$ projeto foi coordenado por Edgar B. Howard, contando com o apoio institucional da Academia de Ciências Naturais da Philadelphia e do Museu da Universidade da Pennsylvania, bem como com o apoio financeiro do Carnagie Institution, de Washington DC. No final de 1932, Howard tinha tomado conhecimento de um rico veio de fósseis exposto pela construção de uma estrada, próximo ao rio Blackwater Draw, localizado ao sul da cidade de Clovis, também no Novo México. As escavações do sítio em Clovis foram iniciadas em maio de 1933 e em julho foram encontrados os primeiros artefatos bifaciais (raspadores, lascas e parte de uma ponta) associados a ossos de bisões e mamutes, com datações estimadas em 15.000 anos AP. Os achados de Clovis (e também do sítio Burnet Cave, com ocupação Folsom) foram objeto da tese de PhD de Howard, defendida na Universidade da

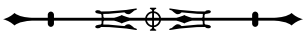


Pennsylvania em 1935, com o título "Evidence of early man in North America" (Meltzer, 2015).

A mudança epistemológica representada por Folsom e Clovis estimulou, em 1934, o primeiro projeto do Smithsonian sobre povoamento, coordenado por Frank Roberts, no sítio Lindenmeier (Colorado), que introduziu o termo 'paleoíndio' na arqueologia americana. Seu impacto também incentivou a busca de sítios semelhantes por profissionais e amadores, tendo sido localizadas nas Grandes Planícies, até o final daquela década, pelo menos duas dúzias de sítios de caça de megafauna extinta (killing sites). Folsom e Clovis também estabelecem uma mudança radical sobre o papel dos estudos arqueológicos para estabelecer a cronologia da ocupação inicial do continente, até então a cabo dos geólogos e dos paleontólogos. As seriações haviam sido introduzidas na arqueologia norte-americana desde o início do século, e a classificação formal de artefatostipo com sensibilidade cronológica (como as pontas de projétil) transformou-se em um instrumento metodológico importante para o estabelecimento das primeiras sequências culturais americanas (Meltzer, 2009, 2015; Sellet, 2011).

Foi somente com a popularização dos métodos de datação absoluta nos anos 1960 que uma barreira cronológica com o nome de Clovis começou a ser construída pelos acadêmicos norte-americanos, vinculados à chamada Nova Arqueologia (Adovasio; Pedler, 2013; Bonnichsen; Lepper, 2005; Meltzer, 2009). Em 1964, C. Vance Haynes Jr. publicou o primeiro artigo sobre datações radiocarbônicas para sítios Clovis (incluindo o sítio-tipo), encontrando-se a maioria das datas entre 11.000 e 11.500 anos AP. Com base nos dados geológicos disponíveis naquele momento, o autor defendeu a hipótese de que a barreira física causada pelo fechamento das geleiras continentais no Último Máximo Glacial (UMG) determinaria também uma barreira cronológica para o povoamento da América. O início do povoamento foi estimado em 12.000 anos AP, quando a abertura do 'corredor livre de gelo' entre as geleiras Larentide e Cordillera teria conectado o Alasca ao interior do continente pela primeira vez em 15.000 anos, permitindo a migração das primeiras populações siberianas para a América do Norte (Haynes Jr., 1964). Complementa o modelo 'Clovis Primeiro' (Clovis First) a hipótese de Paul Martin de que uma rápida colonização do continente foi possível a partir da caça especializada de megafauna, o que, eventualmente, também teria provocado a sua extinção (Overkill Model). A partir deste padrão predatório paleoindígena, um período de 500 anos teria sido suficiente para o povoamento continental, sendo a cultura Clovis a ancestral direta de todas as indústrias líticas da América (Martin, 1973; Mosimann; Martin, 1975).

Em torno dos argumentos centrais destes dois modelos hipotéticos começou a se erguer uma barricada de carvões, pedras e ossos, reascendendo as velhas polêmicas do paleolítico americano. Os argumentos metodológicos do debate passaram a se orientar para a validade dos métodos de datação absoluta (em especial, para os sítios pré-Clovis) e sobre como as indústrias líticas pleistocênicas deveriam se parecer (Meltzer, 1989; Kelly, 2003).

Vale lembrar aqui que a legislação patrimonial norte-americana parte de uma premissa constitucional que garante o direito de propriedade privada sobre recursos culturais, garantida pelas $5^{\mathrm{a}}$ e $14^{\mathrm{a}}$ emendas. Assim, somente $1 / 3$ do território norte-americano é coberto por práticas de gerenciamento protetivas, associadas a terras públicas e indígenas, e só 7\% dessas áreas foram objeto de inventário de bens arqueológicos, sob a coordenação do National Park Services (Hart, 1995; Knudson, 1995). Quanto aos financiamentos dos trabalhos arqueológicos nos EUA, a partir de 1974, com a promulgação do Archaeological and Historic Preservation Act (PL 93-291) (também conhecido como Moss-Bennett Bill), a arqueologia de contrato passou a predominar como fonte regular de recursos e, enquanto - Big Business passou a ditar o que e onde escavar, as pesquisas aplicadas começaram a minguar. Por exemplo, os programas de financiamento federal para arqueologia do National Science Foundation (NSF) receberam, entre os anos 1980 e 1990, em torno de cinco milhões de

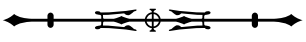


dólares ao ano, mas apenas uma pequena parcela financiou pesquisas sobre povoamento, relacionadas, em geral, a projetos de pós-graduação. Portanto, na prática, boa parte do financiamento das pesquisas aplicadas nas universidades e nos museus norte-americanos depende de doações de particulares (O'Brien et al., 2005; Watson, 1995; Yellen; Greene, 1985).

Partindo-se dessa conjuntura, pode-se entender por que ressuscitar as polêmicas sobre a cronologia do povoamento no final do século $X X$ se tornou um bom negócio nos EUA. Controvérsias científicas sem resolução geram publicações, exposição na grande mídia, convites para eventos, dinheiro para pesquisa, propostas de melhores salários em universidades de maior prestígio e, quem sabe, uma garantia de preservação dos sítios, se a polêmica for quente o suficiente para despertar o interesse local ou, ainda, da UNESCO. E apimentar o debate com doses extras de nacionalismo torna a combinação muito mais vendável para um público simpático a contribuir com projetos que comprovem que a América do Norte sempre está em primeiro lugar.

As décadas de 1970 a 1990 foram os anos de ouro do modelo Clovis First. As primeiras vítimas pré-Clovis foram Calico Hills, na Califórnia, e Meadowcroft, na Pennsylvania, mas logo os ataques se direcionaram à América Central e à América do Sul. Meltzer (2009) contabiliza os mortos: em 1964 existiam no páreo 50 candidatos a sítios pré-Clovis no Novo Mundo, restando apenas cinco em 1988. E a contagem para a América do Sul foi a zero depois dos massacres retóricos perpetrados pela patrulha ideológica de Clovis nas prestigiosas páginas de American Antiquity e de Antiquity (Lynch, 1990, 1991; Meltzer et al., 1994).

Um exemplo do imperialismo acadêmico (Trigger, 1996) desta geração de arqueólogos norte-americanos é oferecido pela seguinte passagem de David Meltzer, ao referir-se às réplicas de Niéde Guidon às críticas ao sítio
Boqueirão da Pedra Furada, cujos termos ela classificou como kafkanianos:

\begin{abstract}
Se eu fosse selecionar uma metáfora de Kafka, não seria o clássico sombrio "O processo", mas sua obra menos conhecida [sic] "A metamorfose", na qual um humano promissor se transforma em uma barata. Virtualmente cada temporada de campo nas últimas décadas trouxe um novo competidor à coroa pré-Clovis. Cada um, inicialmente saldado com uma grande fanfarra, logo escorrega ladeira abaixo da curva de decaimento de credibilidade pré-Clovis. Os problemas variam, mas o resultado é inevitavelmente o mesmo. A maioria dos candidatos pré-Clovis tem uma meia vida de aproximadamente meia década; melhor do que peixes e hóspedes, mas no final eles também começam a feder. (Meltzer, 2009, p. 96, tradução nossa).
\end{abstract}

A posição não poderia ser mais clara. A única relação aceitável entre as arqueologias do povoamento do Norte e do Sul era o espelhamento, sendo tolerados nos limites dos modelos explicativos hegemônicos apenas os contextos cujas cronologias, semelhanças ecológicas e afinidades tecnológicas sustentassem a perspectiva culturalista do modelo Clovis Firts'.

Mas, na virada do século XXI, a limpeza de terreno dos sítios pré-Clovis na América do Sul preparava um plot twist para seguir encantando os patrocinadores: a quebra da barreira Clovis por aqueles que tão diletamente a construíram e defenderam. Em 1997, no aniversário de 70 anos da descoberta de Folsom, foi protagonizada, em Monte Verde, no Chile, a derradeira visita a um candidato a sítio pleistocênico pelos mais aguerridos membros da patrulha Clovis, que realizaram, na frente das câmeras da National Geographic, uma democrática votação favorável às suas datações de 13.000 anos AP (uma datação de 33.000 anos AP do mesmo sítio é um pequeno inconveniente, sobre o qual os presentes preferiram não se manifestar naquele momento). Nas palavras de Meltzer (2009, p. 125, tradução nossa):

\footnotetext{
Como exemplificado pelo livro organizado por Morrow e Gnecco (2006).
}

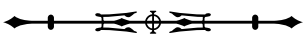


Nós viemos, nós vimos e nós estamos convencidos. E apenas algumas semanas depois de nosso retorno de Monte Verde, em janeiro de 1997, o Museu de História Natural de Dallas e a National Geographic Society (que copatrocinaram a nossa viagem) organizaram uma coletiva de imprensa para anunciar nossa conclusão de que o trabalho de Tom Dillehay em Monte Verde tinha finalmente quebrado a barreira Clovis.

Logicamente, os salões da Society for American Archaeology (SAA) e as páginas da American Antiquity serviram, nos anos seguintes, para selar o acordo que dava a palavra final aos arqueólogos da costa oeste sobre as narrativas do povoamento da América (Meltzer et al., 1997); e, em outubro de 1999, um Congresso foi organizado na terra natal de Clovis pelo Centro de Estudos dos Primeiros Americanos, filiado naquele momento a Oregon State University. Com o promissor título "Paleoamerican origins: beyond Clovis", em torno de 1.200 pessoas compareceram ao evento em Santa Fé, que proclamou oficialmente a morte de Clovis e a coroação de Monte Verde como sítio mais antigo da América, recuando a barreira cronológica do povoamento por mais dois milênios. Mas as coisas não saíram como planejadas: Kennewick Man havia chegado para estragar a festa.

O Native American Graves Protection and Repatriation Act (NAGPRA), de 1990, e o American Indians Religions Freedom Act (AIRFA), de 1996, abriram o debate nos EUA sobre o controle do patrimônio cultural e dos restos biológicos escavados em terras públicas (federais ou indígenas) sob a guarda de museus e universidades. $\bigcirc$ NAGPRA estabeleceu a noção de que a afiliação cultural, como base legal, se dá a partir de bases biológicas, geográficas, arqueológicas, antropológicas, linguísticas, folclóricas e históricas. Assim, as instituições públicas ou beneficiárias de fundos federais foram obrigadas legalmente a colocar à disposição dos grupos tribais materiais de origem nativa para que estes pudessem solicitar a sua devolução às terras indígenas, para exposição nos seus museus ou novo sepultamento. $O$ caso mais polêmico foi Kennewick Man. Encontrado, em 1996, em terras federais no estado de Washington e datado de 9.500 anos AP, este esqueleto parcialmente completo foi reivindicado para sepultamento por três grupos indígenas da região, sob a justificativa de que ele representava o antepassado comum de todas as nações indígenas da América. Ele era The Old One e deveria ser tratado com o devido respeito. A batalha legal que se seguiu entre lideranças indígenas e arqueólogos pelos restos mortais de Kennewick Man permitiu aflorar todas as contradições de uma prática arqueológica descomprometida com as agendas políticas dos nativos americanos. A solicitação foi contestada juridicamente por um grupo de acadêmicos explicitamente alinhados à patrulha Clovis, usando argumentos que vergonhosamente buscavam negar o vínculo entre o passado e o presente da história indígena americana. O caso foi levado à Suprema Corte e Kennewick Man foi finalmente sepultado em 2015, depois de uma longa disputa legal (mas somente após a apresentação de provas genéticas da alegada ancestralidade) (Hutterer, 2015); e junto com ele, foram enterradas as aspirações de grandeza de toda uma geração de arqueólogos que construiu suas carreiras acadêmicas a partir das assimetrias que o modelo Clovis First proporcionou.

Para o bem dos negócios, Clovis precisava ser enterrado de uma vez por todas.

Entre 17 e 19 de outubro de 2013, o Centro de Estudos dos Primeiros Americanos, agora associado ao Texas A\&M University, organizou um novo evento no Novo México, intitulado "Paleoamerican odyssey", para o qual fui convidada para falar sobre arqueologia brasileira. Foi uma escolha inteligente de título. Uma odisseia pode ser definida como a narração de uma longa viagem (de caráter heroico), marcada por aventuras, eventos imprevistos e singularidades; é também uma investigação de caráter intelectual ou espiritual. E nenhum destes ingredientes faltou naqueles três dias de evento, onde velhos e novos personagens desta saga subiram ao palco do Santa Fe Community Convention Center, falando para uma plateia de 1.130 pessoas, entre profissionais (46\% dos inscritos) e aficionados (54\% dos

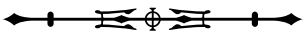


inscritos). Além dos simpósios temáticos integrados por conferencistas convidados que ocorriam nas manhãs e tardes no salão principal, as noites eram ocupadas por sessões de comunicações e mesas de discussão. Sessões de painéis se sucederam nos corredores ao longo de todos os dias do evento e uma exibição de artefatos de mais de 50 sítios arqueológicos Clovis e pré-Clovis pertencentes a museus, universidades e colecionadores particulares estava aberta ao público (Pitblado, 2014).

Porém, diferente da maioria dos eventos sobre o tema, aquele tinha uma narrativa intencionalmente planejada para exorcizar o espírito de Clovis. A sucessão dos simpósios tinha uma cadência que lembrava uma missa de réquiem, voltada a apaziguar os espíritos atormentados do purgatório acadêmico que a pesquisa sobre o povoamento da América havia se transformado nos últimos cinquenta anos. E, assim, a cantilena de cronologias, rotas de dispersão e modelos de povoamento foi organizada em novos arranjos, alguns harmônicos, outros dissonantes, cuja cadência vou tentar reproduzir a seguir.

\section{DIES IRAE 2}

Dies irae, dies illa, Solvet saeclum in favilla; Teste David cum Sibylla. Quantus tremor est futurus, Quantus judex ets venturus, Cuncta stricte discursurus! ${ }^{3}$

A cronologia das rotas do povoamento americano foi o tema que ocupou o primeiro dia de trabalhos. Para nos preparar para o início da jornada espiritual que estava por vir, na abertura do evento foi proferida uma benção pelo Sr. José Lucero, líder espiritual do Pueblo Santa Clara e membro do Traditional Circle of Elders of the Western Hemispher.
O simpósio de abertura tratou da "Grande Beríngia antes do Último Máximo Glacial" e o primeiro a falar foi Vladimir Pitulko, da Academia Russa de Ciências, apresentando as pesquisas que vêm sendo desenvolvidas na costa oeste da Beríngia nos últimos vinte anos, em especial em Yana Rhinoceros Horn Site (RHS). Descoberto em 2001, o sítio Yana apresenta uma lista de 84 datações radiocarbônicas entre 47.000 e 16.000 anos AP e conta uma história profunda da ocupação humana do Ártico que só se interrompeu nos dois milênios do auge do Último Máximo Glacial (UMG), entre 20.000 e 18.000 anos AP. A caça do mamute (ou a busca de suas carcaças) parece ser a principal causa da localização do sítio em alta latitude, especialmente para exploração de marfim (Pitulko et al., 2013).

Uma revisão detalhada da arqueologia siberiana, apresentada na sequência por Graf (2013), reforçou os argumentos favoráveis ao julgamento esperado: o povoamento inicial da América é parte da odisseia do povoamento global dos humanos modernos, que partiram da África há 100.000 anos. Portanto, suas cronologias devem ser atualizadas e sincronizadas aos ritmos hoje conhecidos para o povoamento da Eurásia através da arqueologia e da genética (Gamble, 2013; Stringer, 2012).

Um primeiro pulso de ocupação por humanos modernos na Sibéria se deu entre 50.000 e 30.000 anos AP, em um período de clima mais ameno (interglacial), fixando-se estas populações entre os rios O'b e Lena, a oeste do lago Baikal. Com tecnologia de lâmina, produzindo projéteis e uma variedade de artefatos líticos retocados para o processamento de alimentos, manufatura de roupas e produção de artefatos em osso e marfim, as primeiras ocupações siberianas parecem tratar-se de bases sazonais, com caça diversificada. A população era provavelmente pequena e não há indicações de que tenha

2 A estrutura deste artigo toma por referência trechos do réquiem em ré menor (K.626) de Mozart (1791). A letra da obra citada nas epígrafes deste artigo é a da missa católica romana de encomenda dos mortos (missa de réquiem). As traduções do latim aqui utilizadas podem ser acessadas em Wikipédia (Requiem..., 2019).

3 Dia de ira, nestes dias dissolverão os séculos em cinzas; assim testificam Davi e Sibila. Quanto temor haverá então, quando o Juiz vier, para julgar com rigor todas as coisas!

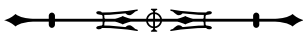


se dispersado para o outro lado da Beríngia neste momento (Graf, 2013; Pitulko et al., 2013).

No período Gravetense, entre 30.000 e 20.000 (34.000-24.000 cal) anos AP, os humanos modernos ocuparam todo o oeste da Eurásia. A distribuição dos sítios se ampliou, formando um amplo triângulo que abrange o sudoeste da Sibéria e o noroeste da Beríngia até o Transbaikal no sudeste, observando-se um sistema de alta mobilidade, com bases residenciais de longa duração e locais de exploração sazonal dos recursos, como representados pelos sítios do Complexo Malta e o sítio Yana. No UMG, a Sibéria parece ter sido abandonada e as pessoas buscaram refúgio no leste da Rússia e no sul, ocupando a península de Hokkaido, no norte do Japão. A diversidade cultural tornouse grande neste momento e a caça de manadas móveis, mais dispersas no final da última glaciação, transformou-se em uma estratégia econômica regular para as populações em crescimento e que já usavam os cães domesticados para caça e tração (como confirmado pelos estudos de DNA canino), sendo a Sibéria repovoada novamente a partir de 17.000 anos AP (Graf, 2013; Izuho, 2013).

Portanto, o registro do Paleolítico Superior na Sibéria sugere pelo menos dois possíveis cenários de dispersão para América. Um provável primeiro momento seria entre 34.000 e 24.000 anos cal AP, que também coincide com o povoamento definitivo da Europa depois da extinção dos neandertais. Um segundo momento seria após o UMG, com datas entre 16.000 anos cal AP (Beríngia) e 14.500 anos cal AP (Alasca), e que estaria possivelmente relacionado ao repovoamento da Sibéria e ao surgimento do Horizonte Clovis. As pesquisas desenvolvidas na Beríngia e no Alasca nas últimas décadas têm demonstrado que a dinâmica populacional nestas áreas se intensificou no Younger-Dryas (12.900-11.500 anos cal AP), incluindo sítios ao longo do 'corredor livre de gelo'. A economia estava focada em grandes mamíferos, em particular no bisão, além de um amplo espectro de animais pequenos e médios e da pesca do salmão. Apesar da ausência de evidências arqueológicas, uma ocupação costeira mais antiga, com adaptação marítima, não pode ser descartada, pois a elevação do nível do mar teria submergido as paisagens possivelmente ocupadas pelos humanos entre $17.000 \mathrm{e}$ 15.000 anos cal AP (Potter et al., 2013; Smith et al., 2013).

O segundo simpósio tratou das "rotas e processos de dispersão". A discussão iniciou com uma atualização cronológica da paleogeografia do 'corredor livre de gelo' entre as geleiras americanas (por John Ives), cujo fechamento atualmente foi revisto para um período de dois milênios, associado ao UMG. A seguir, foram retomados os argumentos dos modelos que defendem as rotas costeiras do Pacífico (por Jon Erlandson, Quentin Mackie e David Anderson) e do Atlântico (por Denis Stanford e Bruce Bradley). As contribuições dos estudos genéticos para essas discussões (por Connie Mulligan e Eske Willerslev) encerraram o primeiro dia do evento.

Pelo paradigma Clovis First, o litoral Pacífico apresentaria condições adversas para o povoamento inicial por estar bloqueado pelas geleiras, e os defensores da rota costeira, em geral, eram ignorados, alegando-se ausência de dados empíricos que sustentassem suas premissas ${ }^{4}$. Atualmente, os estudos genéticos revitalizaram o modelo costeiro e a escassez de evidências arqueológicas no litoral do Pacífico tem sido explicada pela baixa densidade demográfica, aliada à alta mobilidade das populações pioneiras. Outro fator a ser considerado é a destruição dos sítios costeiros pelo aumento do nível do mar e a tectônica de placas no período pós-glacial, justificando os projetos de arqueologia subaquática atualmente em andamento para a identificação e a sondagem das antigas linhas da costa (Mackie et al., 2013). O modelo da rota Pacífica sugere que a subsistência dessas primeiras populações estaria baseada em recursos aquáticos variados e os estuários seriam pontos de 'parada' (rest stops) que conduziriam para o interior através dos rios, atingindo os lagos e

\footnotetext{
4 Como foi o caso dos trabalhos de Gruhn (1988, 1994), Fladmark (1979), Erlandson (2001) e Dixon (2001).
}

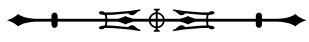


pântanos do planalto da Columbia, da Grande Bacia e do Vale Central da Califórnia. Este modelo de expansão teria seguido ao longo da costa da América Central e, ao chegar ao Istmo do Panamá, as rotas de povoamento teriam tomado duas direções. A rota Paćífica teria seguido rumo ao sul, ocupando também as Terras Altas, e chegando à costa do Chile e da Patagônia entre 13.000 e 12.000 anos AP. Uma rota Atlântica teria se expandido para as Terras Baixas, circundando o Caribe e se interiorizando inicialmente a partir dos vales do Orenoco e do Amazonas, também entre 13.000 e 12.000 anos AP (Anderson et al., 2013; Erlandson, 2013). Por sua vez, as melhores evidências arqueológicas nos EUA da rota Pacífica estariam representadas pela Western Stemmed Tradition (WST), hipótese já levantada por Alan Bryan nos anos 1980 e que agora está sendo retomada a partir das datações de 15.000 anos cal AP do sítio Paisley Caves, no Oregon (Erlandson, 2013; Bryan; Gruhn, 2003; Gruhn; Bryan, 2011). Quanto ao Horizonte Clovis, o modelo costeiro sugere que este teria surgido no Younger-Dryas (13.000 anos cal AP), a partir de migrações pelo 'corredor livre de gelo' (Beck; Jones, 2013; Ives et al., 2013; Jenkins et al., 2013).

A rota Atlântica foi defendida no final dos anos 1990 por Bruce Bradley, Michael Collins e Dennis Stanford, angariando apoio dos simpatizantes do modelo Clovis First. Seus proponentes imaginam Clovis como um movimento de revitalização da cultura Solutrense, que floresceu no leste da Europa no auge do UMG (Bradley; Collins, 2013; Collins et al., 2013) e cuja presença na América estaria atestada pelas datações de sítios pré-Clovis na costa leste norte-americana, como Cactus Hill e Miles Point. Este modelo também foi utilizado como um dos argumentos científicos no debate de Kennewick Man, para justificar sua alegada ausência de relação biológica com as atuais populações indígenas americanas, atestada pela morfologia craniana com características 'mais caucasoides'. Devido às implicações políticas deste modelo, que ressuscita os argumentos raciais poligenistas do início do século $X X$, ele foi alvo de duras críticas, principalmente dos geneticistas. Os estudos genéticos de esqueletos antigos e de populações vivas têm demonstrado que os ameríndios se originaram de uma única população no nordeste da Ásia, o que invalida os argumentos centrais do modelo pela rota Atlântica, embora a cronologia desta origem alimente outras controvérsias (O'Rourke; Raff, 2010; Raff; Bolnick, 2015).

O modelo de povoamento da América sugerido pelos estudos da origem dos haplogrupos americanos tem uma estimativa cronológica conservadora, indicando três pulsos populacionais possíveis. A partir de 40.000 anos AP, teria ocorrido uma separação da população original centroasiática que teria sofrido diversificação genética no UMG em função de isolamento populacional na Beríngia, dando origem à diversidade mitocondrial observada entre os nativos americanos atuais. Por fim, uma expansão genética teria ocorrido entre 16.000 e 12.000 anos AP, quando uma população fundadora, estimada em mil indivíduos, teria entrado na América, com crescimento populacional rápido (Mulligan; Kitchen, 2013).

Cabe lembrar que uma proposta que apóia dinâmicas populacionais mais antigas do que as estimadas pelos modelos genéticos foi defendida por Walter Neves e colaboradores nos anos 1990, através do 'modelo dos dois componentes biológicos'. Partindo do estudo da diversidade da morfologia craniana ameríndia no tempo e no espaço, o modelo sugere um fluxo populacional pleistocênico, contemporâneo ao povoamento da Austrália, seguido por outro fluxo pós-glacial, responsável por fixar as características modernas das populações ameríndias (Neves et al., 1997; Hubbe et al., 2010). Este modelo tem sofrido severas críticas, devido à homogeneidade genética dos grupos contemporâneos, mas estudos recentes entre as populações patagônicas têm demonstrado uma possível origem de haplogrupos locais entre 25.000 e 19.000 anos cal AP (Saint Pierre, 2017). Ao que tudo indica, no século XXI, as disputas na bioantropologia para explicar como o tempo moldou os corpos nativos está delimitando uma nova trincheira

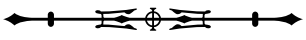


acadêmica na batalha entre norte e o sul pelo domínio das narrativas sobre o povoamento americano.

\section{LACRIMOSA}

Lacrimosa, dies illa, Qua resurget ex favilla. Judicandus homo reus: Huic ergo parce, Deus.

Pie Jesu Domine,

Dona eis requiem.

$A m e n^{5}$

O simpósio da manhã seguinte se chamava, simplesmente, Clovis. Mas não havia nada de simples ali. O salão principal estava cheio e o público, animado para rever as velhas e as novas polêmicas que Clovis tinha a oferecer. $\mathrm{Na}$ arena principal estava presente o debate sobre a extinção da megafauna (Waguespack, 2013) e, novamente, foi discutido o impávido modelo da rota Atlântica (Bradley; Collins, 2013). Novas polêmicas também marcaram presença para alegrar o público: as mudanças climáticas do Younger-Dryas teriam sido causadas por um evento de impacto cósmico que acabou com a cultura Clovis? As análises sobre o fenômeno Clovis, sob a perspectiva do território, da subsistência, da variabilidade regional e do comportamento simbólico, completaram a manhã (Haynes; Hutson, 2013; Holliday; Miller, 2013; Joyce, 2013; Kilby; Huckell, 2013; Miller et al., 2013). A comunidade mantenedora da honra de Clovis dava sinais claros de que não ia desistir sem luta de seu confortável isolamento, e o tema principal das dezenas de painéis que se sucederam pelos corredores ao longo do evento não deixavam dúvida de que Clovis ainda tinha muito para dar.

Quando os trabalhos da tarde se iniciaram, o burburinho no salão era grande. O simpósio se chamava "os contemporâneos de Clovis na América do Sul" e aquele que todos esperavam ouvir era Tom Dillehay, que deveria falar sobre seu novo projeto na costa do Peru
(Dillehay, 2013). Mas o tema da conversa acabou voltando novamente para Clovis. Descontente com as bravatas que Stuart Fiedel havia disparado na imprensa naquela semana sobre as possíveis contribuições tecnológicas dos primatas para a formação dos sítios arqueológicos pleistocênicos na América do Sul ${ }^{6}$, Dillehay começou sua fala com a projeção da imagem de um macaco-prego e, depois de tecer algumas críticas à patrulha Clovis e proferir alguns palavrões, saiu intempestivamente da sala, acompanhado por boa parte da audiência, pouco interessada nas contribuições das pesquisas latino-americanas para o debate, um tema considerado secundário pela ortodoxia (Borrero, 2016).

$\mathrm{Na}$ sequência, a antiguidade do povoamento inicial do México foi debatida a partir dos dados de oito esqueletos humanos encontrados em cavernas submersas na península de Yucatan (González, A. et al., 2013). Com datações entre 13.000 e 8.000 AP, estes achados situamse em uma posição cronológica bem mais confortável para uma perspectiva conservadora do que as datações de 40.000 anos obtidas para pegadas humanas em cinzas vulcânicas, encontradas em Vasequillo, ao sul de Puebla, exaustivamente escrutinadas pelos próprios autores até serem 'riscadas da lista' dos sítios mais antigos da América (González, S. et al., 2006; Morse et al., 2010; Lucas, 2017).

No entanto, deve-se destacar que os critérios para avaliação de sítios Clovis da América do Norte sempre foram bem menos rigorosos do que os empregados para os contextos latino-americanos, e avaliações recentes de datações para sítios norte-americanos indicam que somente 30 sítios têm datações associadas à faixa cronológica compatível ao Horizonte Clovis (13.250 a 12.800 anos cal AP). Deste conjunto, apenas 11 sítios apresentam artefatos Clovis em contextos geológicos considerados 'seguros' (associados a 43 datações radiocarbônicas), 14 sítios têm associação contextual com restos de mamutes e mastodontes, e somente seis sítios foram identificados

\footnotetext{
5 Dias de lágrimas, naqueles dias, no qual ressurgirá das cinzas, um homem para ser julgado. Portanto, poupe-o, ó Deus. Ó, misericordioso, Senhor Jesus, repouso terno dá-lhes. Amém.

6 Para os muito curiosos, ver Fiedel (2017).
}

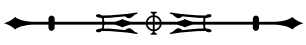


por arqueólogos profissionais em projetos de pesquisa voltados ao estudo do povoamento americano, sendo o restante localizado por colecionadores de artefatos em áreas privadas (Greyson; Meltzer, 2002; Hall et al., 2002; Pitblado, 2014; Waters; Stafford Jr., 2007). Ainda, os dados utilizados para a construção de modelos de mobilidade, demografia e cronologia de colonização associados ao Horizonte Clovis têm se baseado, principalmente, na distribuição e abundância regional das pontas de projétil acaneladas, registradas a partir do Paleoindian Database of the Americas (PIDBA) (Anderson; Gilliam, 2000; Anderson; Miller, 2017; Kelly; Todd, 1988; Morrow, J.; Morrow, T., 1999). Estes trabalhos partem da premissa de que a densidade das pontas de projétil reflete padrões demográficos antigos; porém, as amostras regionais demonstram que a maior presença de pontas Clovis no sudeste dos EUA está relacionada a uma variedade de fatores modernos, tais como a densidade populacional, a urbanização, as práticas de cultivo, a visibilidade geológica, a produtividade ambiental, a intensidade da pesquisa arqueológica e, principalmente, os esforços de coleta de artefatos por amadores em áreas privadas e seu desejo de compartilhar estes dados com os arqueólogos (Prasciunas, 2011).

Essa política acadêmica de 'dois pesos, duas medidas' da patrulha Clovis, se, por um lado, contribuiu para mascarar a fragilidade de dados que sustentam o modelo hegemônico, por outro, acabou por gerar um efeito colateral, ao fim positivo para arqueologia sulamericana. Às margens de Clovis foi se construindo, nos últimos 25 anos, um modelo de povoamento da América do Sul muito distinto do ortodoxo, a partir dos esforços de redes internacionais de pesquisadores, associadas ao crescimento dos programas de pós-graduação locais, aos maiores investimentos públicos e privados (através da arqueologia de contrato) para projetos arqueológicos e pelo aumento do número de associações, eventos e periódicos científicos, que têm permitido uma circulação mais livre e abundante de informações para além do controle e da tutela da Society for American Archaeology (SAA). Geoarqueologia, tafonomia e microestratigrafia são os marcos de análise que têm sustentado as construções destes modelos de povoamentos 'extra-Clovis' nas últimas décadas, favorecidos também pela atual facilidade de acesso a datações por AMS em laboratórios de referência internacional. Como resultado, hoje se percebe que o modelo de povoamento da América do Sul é uma imagem invertida de Clovis, cuja diversidade cultural subverte a ordem determinada pelo modelo hegemônico: não existe pecado do lado de baixo do Equador (Dias, 2004).

Entre 13.000 e 7.000 anos AP, o processo de construção territorial na América do Sul abrangeu, simultaneamente, distintos ecossistemas, como a costa desértica do Pacífico, o Altiplano, as florestas amazônica e atlântica, as áreas alagadiças do Pantanal e as savanas tropicais do centro do continente, além das pradarias do Cone Sul ${ }^{7}$. Os dados paleoclimáticos indicam que os biomas tropicais na América do Sul não foram significativamente afetados pela aridez e pelo declínio das temperaturas durante o UMG, e as pesquisas arqueológicas têm indicado que a presença das florestas não representou uma barreira às primeiras ocupações humanas, como previsto pelo modelo ortodoxo (Gnecco, 2000; Lanata et al., 2008).

A maior intensidade das pesquisas sobre estes primeiros povoamentos tem se dado no Brasil, com 277 datas radiocarbônicas entre 13.000 e 8.000 anos AP para 90 sítios arqueológicos (Bueno et al., 2013b), e na Argentina, com 274 datações radiocarbônicas entre 13.000 e 7.000 anos AP, associadas a 72 sítios arqueológicos (Prates et al., 2013). Estes dados, no entanto, seguem sendo tratados em tons monotônicos nos modelos de povoamento elaborados à sombra de Clovis.

\footnotetext{
7 Ver coletânea de artigos organizada por Bueno et al. (2013a) e que oferece dados comparativos para diferentes contextos sul-americanos, como Brasil, Uruguai, Argentina, Bolívia, Chile, Peru e Colômbia, incluindo também Panamá.
}

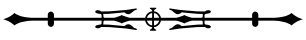


No caso da Argentina, as discussões apresentadas por Nora Flegenheimer naquela tarde sobre construção de territórios no Pampa e na Patagônia, partindo de um universo de dados bem mais consistentes e complexos do que os utilizados para as modelagens Clovis (Flegenheimer et al., 2013), ainda têm pouco impacto frente à 'tirania tipológica' dos modelos de mobilidade regional centrados na distribuição geográfica de pontas de projétil como vetores para pensar difusão cultural (Bradley, 2015). No caso do Brasil, a diversidade regional a partir do Holoceno inicial é ignorada nos modelos de povoamento continental que enfatizam, obsessivamente, os sítios com datações pleistocênicas. Um exemplo deste impacto negativo está na ausência de diálogo entre os modelos genéticos com os extensos dados de pesquisa para a região de Lagoa Santa, também apresentados no simpósio da tarde por Mark Hubbe, e que oferecem uma robusta base de dados para sustentar o 'modelo dos dois componentes biológicos', associada à maior coleção americana de esqueletos humanos antigos (cerca de 300 indivíduos), com 79 datações radiocarbônicas entre 10.460 e 8.040 anos AP para 15 sítios arqueológicos escavados nas últimas décadas (Neves et al., 2013).

Outro exemplo está na centralidade dos modelos costeiros de povoamento da América do Sul, com ênfase na costa Pacífica, em função de Monte Verde, que desconsideram a imensa diversidade de tramas culturais que estavam se desenrolando simultaneamente ao leste dos Andes e tendo por cenário os ambientes tropicais e seus sistemas fluviais. É este o tema de pesquisa que venho trabalhando com Lucas Bueno e que eu trouxe para a conversa naquele fim de tarde, em um salão já quase vazio, cujos argumentos retomo a seguir (Dias; Bueno, 2013; Bueno et al., 2013b; Bueno; Dias, 2015).

Em termos cronológicos, a diversidade observada nas Terras Baixas do leste da América do Sul implica necessariamente uma ocupação mais antiga do que o previsto pelos modelos tradicionais. A possibilidade de que o processo de povoamento original tenha se dado antes do UMG é indicada tanto por sítios na costa Pacífica (Monte Verde) quanto por sítios continentais associados aos principais sistemas fluviais do leste, como a bacia do rio da Prata (sítio Santa Elina), a bacia do São Francisco (sítios da Serra da Capivara e do Peruaçu) e a bacia amazônica (Caverna da Pedra Pintada). Independente das discussões tafonômicas que as datações entre 27.000 e 12.000 anos AP destes sítios implicam, suas assinaturas arqueológicas são discretas, indicando uma fase pioneira de exploração do território, caracterizada por baixa densidade demográfica e na qual alguns lugares específicos eram selecionados para ocupação recorrente, como pontos estratégicos das paisagens que estavam começando a ser mapeadas.

Por outro lado, a estabilidade climática do Holoceno inicial é acompanhada por uma expansão e diversificação dos biomas tropicais, desenvolvendo-se a partir daí uma nova fase de estabelecimento de territórios, com fronteiras culturais mais claramente definidas. $O$ aumento demográfico reflete-se no crescimento do número de sítios arqueológicos entre 11.500 e 8.000 anos AP, incluindo as bacias hidrográficas do rio São Francisco (que conecta as rotas pioneiras de ocupação da costa norte do Atlântico com o centro do Brasil), do Amazonas (que conecta as rotas pioneiras de ocupação do platô das Guianas, Venezuela e Colômbia também com o centro do Brasil) e do rio da Prata (que conecta o leste dos Andes à costa atlântica e à bacia amazônica). Baseando-se na exploração generalista de recursos das florestas e das savanas tropicais, as dinâmicas populacionais tornaram-se complexas e diversificadas, expressando-se em uma ampla gama regional de manifestações tecnológicas e artísticas, o que indicaria um processo intenso de demarcação territorial. Para além do debate sobre as cronologias pleistocênicas do Boqueirão da Pedra Furada, o contexto arqueológico brasileiro demonstra ter muito a oferecer para a construção de modelos do povoamento das regiões tropicais no Holoceno inicial e não poderia estar mais na contramão do que os padrões impostos pelo seu contemporâneo, Clovis. Amém!

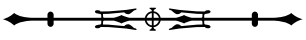




\section{AGNUS DEI}

Agnus Dei,

qui tollis peccata mundi, dona eis requiem sempiternam ${ }^{8}$

O último dia do evento foi dedicado a 'tirar do armário' uma legião de sítios proscritos pelo modelo Clovis First. Novos e velhos sítios pré-Clovis desfilaram em parada para apreciação da plateia: Paisley Caves (por Dennis Jenkins), Meadowcroft (por James Adovasio), Topper (por Albert Goodyear), Debra Friedkin (por Michel Waters) e o Boqueirão da Pedra Furada (por Eric Boëda). As críticas sobre tecnologia e geoarqueologia dos contextos Pleistocênicos completaram as discussões, mas foram amenas. $\bigcirc$ clima era de conciliação e as datações entre 22.000 e 25.000 anos AP para os novos sítios escavados na Serra da Capivara por Eric Boëda foram aceitas com quase naturalidade (repetindo-se o feito nas páginas de Antiquity no ano seguinte). Os dados das escavações dos sítios Vale da Pedra Furada, Tira Peia e Sítio do Meio confirmam e reforçam as mesmas conclusões sobre o sítio do Boqueirão da Pedra Furada, fortemente atacadas pela patrulha Clovis nos anos 1990, mas os tempos (ou talvez os emissários das notícias) são outros (Boëda et al., 2013, 2014); e a 'puxada de orelha' do editorial da revista Nature, em 2012, que classificou o debate sobre o povoamento da América como "[...] bad for Science [...]", certamente ajudou (Dillehay, 2013, p. 392). De qualquer forma, a datação de 33.000 anos AP para os níveis inferiores de Monte Verde é uma 'carta na manga' que ainda coloca Tom Dillehay (e os norte-americanos) na frente do páreo pela descoberta do sítio mais antigo da América. Ou seja, mais do mesmo (Dias; Bueno, 2014).

Adovasio, espirituosamente, chamou o atual momento das pesquisas sobre o povoamento na arqueologia norteamericana como o da 'volta dos que não foram' (Adovasio; Pedler, 2013). Os principais competidores a sítios mais antigos da América do Norte hoje são:
1) Meadowcroft (abrigo sob rocha, Pennsylvania), cuja cronologia radiocarbônica entre 12.000 e 20.000 anos AP é defendida com unhas e dentes há 40 anos por James Adovasio;

2) Cactus Hill (paleoduna, na Virgínia), escavado nos anos 1990 por McAvoy e Johnson e com datações em OSL (Optically Stimulated Luminescence) de 17.000 anos AP;

3) Sítios Debra L. Friedkin e Gault (planície aluvial de Buttermilk Creek, Texas), escavados por Michael Waters, e que apresentam, abaixo dos componentes Clovis da estratigrafia, datas por OSL entre 16.170 e 14.350 anos AP (Waters; Stafford Jr., 2013);

4) Complexo Chesrow (Lago Michigan, Wisconsin), compreendendo 35 sítios identificados na década de 2000, com restos de megafauna e datações entre 12.600 e 13.400 (15.000-16.000 cal) anos AP, destacando-se os sítios Schaefer e Hebior;

5) Paisley Caves (Lago Summer, Oregon), escavado por Jerkins entre 2002 e 2012 e com datações de 12.400 (14.865 cal) anos AP para cinco coprólitos humanos (Jenkins et al., 2013). Paisley Cave leva vantagem nesta disputa. Em uma inusitada pesquisa de opinião realizada em 2012 entre os membros da SAA, ele é o sítio pré-Clovis da América do Norte com maior aprovação, com 43\% dos votos a favor dos seus coprólitos (Wheat, 2012).

E encaminhando os arranjos finais daquele réquiem para Clovis, foi trazida de volta à cena a 'hipótese ecológica da colonização da Estepe do Mamute'. Desenvolvido originalmente por Guthrie (2001) e rejeitado sumariamente pela patrulha Clovis, este modelo foi retomado por Holen, S. e Holen, K. (2013) a partir de estudos recentes no Alasca. Os dados paleoecológicos analisados indicam que entre 65.000 e 27.000 anos AP, no OIS3 (Oxygen Isotope Stage 3), havia uma pradaria contínua, com biota diversificada e homogênea, estendendo-se desde o centro da Europa até a Sibéria (Mammoth Steppe) e daí seguindo pela Beríngia para o Alasca e o Yukon, para a

\footnotetext{
8 Cordeiro de Deus, que tira os pecados do mundo, dai-lhes o repouso eterno.
}

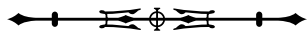


costa pacífica e para o 'corredor livre de gelo', chegando até as Grandes Planícies e o México Central (formando aí a American Steppe). A hipótese propõe que os grupos humanos do Paleolítico Superior se adaptaram a Estepe do Mamute, entre 40.000 e 30.000 anos AP (Aurignacense), em um período de melhoria climática que criou pastagens contínuas em torno das geleiras, capazes de sustentar uma fauna abundante, incluindo bisões, mamutes, rinocerontes lanosos, caribus, cavalos e antílopes saiga. Este modelo sugere que um primeiro povoamento da América pode ter se dado no OIS3, quando as populações do norte da Sibéria se dispersaram pela Beríngia e daí para a borda leste das Montanhas Rochosas.

$O$ 'corredor livre de gelo' entre a Sibéria e o interior da América teria existido até 20.000 anos AP, permitindo a circulação contínua de animais e pessoas entre os dois continentes. Estas primeiras populações seriam pequenas e teriam deixado um registro arqueológico discreto na América do Norte, mas nada impediria que o aumento demográfico e a diversidade cultural tenham se dado de forma contínua, na medida em que os humanos passaram a colonizar os territórios ao sul das geleiras.

Este último simpósio foi encerrado com uma avaliação otimista, realizada por Michael Waters, que defendeu a necessidade de construção de novos modelos para o povoamento americano que incorporem os dados dos sítios pré-Clovis das Américas do Norte e do Sul, bem como considerem a diversidade tecnológica e adaptativa envolvida no processo de colonização continental. As conclusões de Waters, no entanto, ainda partem de uma cronologia conservadora e, tomando por referência os modelos genéticos, ele sugere que o povoamento inicial da América teria "[...] começado por cerca de 16.000 anos cal BP e [...] que por volta de 13.000 anos cal AP, a tecnologia Clovis surge e se expande no Hemisfério Norte [...]" (Waters; Stafford Jr., 2013, p. 577, tradução nossa).
No final, Clovis First estava exorcizado, mas a barreira cronológica ainda se manteve firme.

Embora os simpósios deste último dia tivessem sido pensados como um momento de redenção, os ânimos foram ficando cada vez mais exaltados ao longo do dia, com os mesmos debates acalorados entre velhos inimigos, somandose a isso os novos desconfortos dos defensores de Clovis frente às novidades trazidas à cena. O clima foi ficando cada vez mais tenso e as bênçãos proferidas no encerramento do evento pelo Sr. José Lucero tiveram que ser reforçadas, para garantir que o espírito de Clovis First não se manifestasse mais. Depois de uma avaliação final do evento, promovida por uma mesa redonda cacofônica da qual participaram um arqueólogo bastante ortodoxo (Robert Kelly), uma arqueóloga quase heterodoxa (Bonnie Pitblado), um arqueólogo muito latino (Luis Borrero) e um geneticista um tanto deslocado (Dennis O'Rourke), e de uma fala de encerramento emocionada de Waters, clamando por mentes abertas, todos os presentes (talvez umas 500 pessoas) foram convidados pelo Sr. Lucero a se levantar, formar um círculo no enorme salão e dar as mãos. Os elders da arqueologia do povoamento (Stanford, Adovasio, Waters) foram convidados para ficarem no centro da roda, onde foram defumados. O Sr. Lucero pediu, então, que eles se cumprimentassem respeitosamente, agradecessem por estar ali e pedissem desculpas pelas ofensas proferidas. Depois, ele pediu que cumprimentassem cada uma das pessoas que estavam no círculo antes que pudessem sair da sala e que todos nós repetíssemos este gesto, seguindo no mesmo sentido, até a porta de saída.

Foi um longo adeus para Clovis. Que descanse em paz.

\section{LUX AETERNA: PALAVRAS FINAIS}

Lux aeterna luceat eis, Domine: Cum Sanctus tuis in aeternum: quia pius es. Requiem aeternam dona eis, Domine: et lux perpetua luceat eis ${ }^{9}$

9 Que a luz eterna os ilumine, Senhor: com os teus Santos na eternidade, pois és piedoso. Repouso eterno dá-lhes, Senhor, e que a luz perpétua os ilumine.

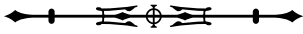


A mensagem final do evento foi esta: para explicar os processos de povoamento inicial da América precisamos abandonar o paradigma Clovis First e todo o comportamento tóxico que dele emana. No banquete de encerramento, a homenagem para Ruth Gruhn e a escolha do tema da conferência ("Ocupando novas terras: migrações globais e diversificação cultural") deram os acordes finais daquele réquiem para Clovis. Hiscock (2013, p. 10, tradução nossa), ao falar sobre o povoamento da Austrália enquanto comíamos a sobremesa, apontou o novo caminho que poderíamos explorar para uma arqueologia do povoamento americano do século XXI:

[...] a variação cultural que emerge [...] não é resultado da manutenção conservadora da tradição social ou de uma diminuição do conjunto de práticas culturais que se seguiram a uma série de eventos fundadores, mas a radiação de práticas e perspectivas culturais como resposta adaptativa a ocupação de novas terras [...]

É uma bela proposta para um recomeço, mas acredito que pouca gente ouviu. Todos queriam relaxar depois da batalha e um público satisfeito, meio bêbado e de barriga cheia, começou a arrastar as cadeiras e a se dispersar, ansioso para voltar para casa, depois de mais um belo espetáculo.

\section{AGRADECIMENTOS}

Ao Programa CAPES/Cofecub (processo número 840/2015), por oportunizar o ambiente intelectual que deu origem a este trabalho, e aos companheiros nesta jornada tão produtiva e prazerosa: Andrei Isnardis Horta, Antoine Lourdeau, Águeda Vilhena-Vialou, Claide de Paula Morais, Denis Vialou e Lucas Bueno.

\section{REFERÊNCIAS}

ADOVASIO, James M.; PEDLER, David R. The ones that still won't go away: more biased thoughts on the pre-Clovis peopling of the New World. In: GRAF, Kelly; KETRON, Caroline V.; WATERS, Michael R. (ed.). Paleoamerican Odyssey. College Station: Texas A\&M University, 2013. p. 511-520.
ANDERSON, David G.; MILLER, D. Shane. PIDBA (Paleoindian Database of the Americas): call for data. PaleoAmerica, London, v. 3, n. 1, p. 1-5, Jan. 2017. DOI: https://doi.org/10.1080/2055556 3.2016.1270154

ANDERSON, David G.; BISSET, Thaddeus G.; YERKA, Stephen I. The Late-Pleistocene human settlement of interior north America: the role of physiography and sea-level change. In: GRAF, Kelly; KETRON, Caroline V.; WATERS, Michael R. (ed.). Paleoamerican Odyssey. College Station: Texas A\&M University, 2013. p. 183-203.

ANDERSON, David G.; GILLAM, J. Christopher. Paleoindian colonization of the Americas: implications from an examination of physiography, demography, and artifact distribution. American Antiquity, Cambridge, v. 65, n. 1, p. 43-66, Jan. 2000. DOI: https:// doi.org/10.2307/2694807.

BECK, Charlotte; JONES, George. Complexities of the colonization process: a view from North American West. In: GRAF, Kelly; KETRON, Caroline V.; WATERS, Michael R. (ed.). Paleoamerican Odyssey. College Station: Texas A\&M University, 2013. p. 273-292.

BOËDA, Eric; CLEMENTE-CONTE, Ignacio; FONTUGNE, Michel; LAHAYE, Christelle; PINO, Mario; FELICE, Gisele Daltrini; GUIDON, Niède; HOELTZ, Sirlei; LOURDEAU, Antoine; PAGLI, Marina; PESSIS, Anne-Marie; VIANA, Sibeli; COSTA, Amélie da; DOUVILLE, Eric. A new late Pleistocene archaeological sequence in South America: the Vale da Pedra Furada (Piauí, Brazil). Antiquity, Cambridge, v. 88, n. 341, p. 927-955, Sept. 2014. DOI: https://doi. org/10.1017/S0003598X00050845.

BOËDA, Eric; LORDEAU, Antoine; LAHAYE, Christelle; FELICE, Gisele Daltrine; VIANA, Sibele; CLEMENTE-CONTE, Ignacio; PINO, Mario; FONTUGNE, Michel; HOELTZ, Sirlei; GUIDON, Niède; PESSIS, Anne-Marie; COSTA, Amélie da; PAGLI, Marina. The Late Pleistocene Industries of Piauí, Brazil: New Data. In: GRAF, Kelly; KETRON, Caroline V.; WATERS, Michael R. (ed.). Paleoamerican Odyssey. College Station: Texas A\&M University, 2013. p. 445-465.

BONNICHSEN, R.; LEPPER, Bradley. Changing perceptions of Paleoamerican prehistory. In: BONNICHSEN, Robson: LEPPER, Bradley T.; STANFORD, Dennis; WATERS, Michael R. Paleoamerican Origins: Beyond Clovis. College Station: Texas A\&T University Press, 2005. p. 9-22.

BORRERO, Luis Alberto. Ambiguity and Debates on the Early Peopling of South America. PaleoAmerica, London, v. 2, n. 1, p. 11-21, Mar. 2016. DOI: https://doi.org/10.1080/20555563.2015.1 136498.

BRADLEY, Bruce. The two Cs: Cola de Pescado and Clovis. PaleoAmerica, London, v. 1, n. 2, p. 127-130, Apr. 2015. DOI: https://doi.org/10.1179/2055556315Z.00000000014.

BRADLEY, Bruce A.; COLLINS, Michael B. Imagining Clovis as a cultural revitalization movement. In: GRAF, Kelly; KETRON, Caroline V.; WATERS, Michael R. (ed.). Paleoamerican Odyssey. College Station: Texas A\&M University, 2013. p. 247-255.

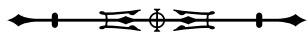


BRYAN, Alan L.; GRUHN, Ruth. Some difficulties in modeling the original peopling of the Americas. Quaternary International, Amsterdam, v. 109/110, p. 175-179, 2003. DOI: https://doi. org/10.1016/S1040-6182(02)00211-2.

BUENO, Lucas; DIAS, Adriana Schmidt. Povoamento inicial da América do Sul: contribuições do contexto brasileiro. Estudos Avançados USP, São Paulo, v. 29, n. 83, p. 119-147, jan./abr. 2015. DOI: http://dx.doi.org/10.1590/S0103-40142015000100009.

BUENO, Lucas; PRATES, Luciano; POLITIS, Gustavo; STEELE, James. A Late Pleistocene/Early Holocene archaeological 14C database for South America and the Isthmus of Panama: Palaeoenvironmental contexts and demographic interpretations. Quaternary International, Amsterdam, v. 301, n. 8, p. 1-2, July 2013a. DOI: https://doi.org/10.1016/j.quaint.2013.04.008.

BUENO, Lucas; DIAS, Adriana Schmidt; STEELE, James. The Late Pleistocene/Early Holocene archaeological record in Brazil: A geo-referenced database. Quaternary International, Amsterdam, v. 301, n. 8, p. 74-93, July 2013b. DOI: https://doi.org/10.1016/j. quaint.2013.03.042.

COLLINS, Michael B.; STANFORD, Dennis J.; LOWERY, Darrin L.; BRADLEY, Bruce A. North America before Clovis: variance in temporal/Spatial cultural patterns (27,000-13,000 cal yr BP). In: GRAF, Kelly; KETRON, Caroline V.; WATERS, Michael R. (ed.). Paleoamerican Odyssey. College Station: Texas A\&M University, 2013. p. 521-539.

DIAS, Adriana Schmidt; BUENO, Lucas. More of the same. Antiquity, Cambridge, v. 88, n. 341, p. 943-945, Sept. 2014. DOI: https://doi.org/10.1017/S0003598X00050869.

DIAS, Adriana Schmidt; BUENO, Lucas. The initial colonization of South America Eastern Lowlands: Brazilian archaeology contributions to settlement of Americas models. In: GRAF, Kelly; KETRON, Caroline V.; WATERS, Michael R. (ed.). Paleoamerican Odyssey. College Station: Texas A\&M University, 2013. p. 339-357.

DIAS, Adriana Schmidt. Diversificar para poblar: el contexto arqueológico brasileño en la transición Pleistoceno-Holoceno. Complutum, Madrid, v. 15, p. 249-263, sem. 2004.

DILLEHAY, Tom D. Entangled Knowledge: old trends and new thoughts in first South America studies. In: GRAF, Kelly; KETRON, Caroline V.; WATERS, Michael R. (ed.). Paleoamerican Odyssey. College Station: Texas A\&M University, 2013. p. 377-395.

DIXON, E. James. Human colonization of the Americas: timing, technology and process. Quaternary Science Reviews, Amsterdam, v. 20, n. 1/3, p. 277-299, Jan. 2001. DOI: https://doi.org/10.1016/ S0277-3791(00)00116-5.

ERLANDSON, Jon M. After Clovis-First collapsed: reimagining the peopling of the Americas. In: GRAF, Kelly; KETRON, Caroline V.; WATERS, Michael R. (ed.). Paleoamerican Odyssey. College Station: Texas A\&M University, 2013. p. 127-132.
ERLANDSON, Jon $M$. The archaeology of aquatic adaptations: paradigms for a new millennium. Journal of Archaeological Ressearch, Berlin, v. 9, n. 4, p. 287-305, Dec. 2001.

FIEDEL, Stuart J. Did monkeys make the Pre-Clovis pebble tools of Northeastern Brazil? PaleoAmerica, London, v. 3, n. 1, p. 6-12, Feb. 2017. DOI: https://doi.org/10.1080/20555563.2016.1273000.

FLADMARK, Knut R. Routes: alternate migration corridors for early man in North America. American Antiquity, Cambridge, v. 44, n. 1, p. 55-69, Jan. 1979. DOI: https://doi.org/10.2307/279189.

FLEGENHEIMER, Nora; MIOTTI, Laura; MAZZIA, Natalia. Rethinking early objects and landscapes in the southern cone: fishtail points concentrations in the Pampas and northern Patagonia. In: GRAF, Kelly; KETRON, Caroline V.; WATERS, Michael R. (ed.). Paleoamerican Odyssey. College Station: Texas A\&M University, 2013. p. 359-376.

GAMBLE, Clive. Settling the Earth: the Archaeology of Deep Human History. New York: Cambridge University Press, 2013.

GNECCO, Cristobal. Ocupacion Temprana de Bosques Tropicales de Montaña. Popayán: Universidad del Cauca, 2000.

GONZÁLEZ, Arturo H.; TERRAZAS, Alejandro; STINNESBECK, Wolfgang; BENAVENTE, Martha E.; AVILÉS, Jerónimo; ROJAS, Carmen; PADILLA, José Manuel; VELÁSQUEZ, Adriana; ACEVEZ, Eugenio; FREY, Eberhard. The first human settlers on the Yucatan Peninsula: evidence from drowned caves in the state of Quintana Roo (South Mexico). In: GRAF, Kelly; KETRON, Caroline V.; WATERS, Michael R. (ed.). Paleoamerican Odyssey. College Station: Texas A\&M University, 2013. p. 323-337.

GONZÁLEZ, Silvia; HUDDART, David; BENNETT, Matthew R.; GONZÁLEZ-HUESCA, Alberto. Human footprints in Central Mexico older than 40,000 years. Quaternary Science Reviews, Amsterdam, v. 25, n. 3/4, p. 201-222, Feb. 2006. DOI: https://doi. org/10.1016/j.quascirev.2005.10.004.

GRAF, Kelly E. Siberian Odyssey. In: GRAF, Kelly; KETRON, Caroline V.; WATERS, Michael R. (ed.). Paleoamerican Odyssey. College Station: Texas A\&M University, 2013. p. 65-80.

GREYSON, Donald K.; MELTZER, David J. Clovis hunting and large mammal extinction: a critical review of the evidence. Journal of World Prehistory, Berlin, v. 16, n. 4, p. 313-359, Dec. 2002.

GRUHN, Ruth; BRYAN, Alan. A current view of the initial peopling of the Americas. In: VIALOU, Denis (ed.). Peuplements et Préhistoire en Amériques. Paris: Comité des Travaux Historiques et Scientifiques, 2011. p. 17-30. (Documents Préhistoriques).

GRUHN, Ruth. The Pacific Coast Route of initial entry: an overview. In: BONNICHSEN, Robson; STELLE, D. Gentry. Method and Theory for Investigating the Peopling of the Americas. College Station: Center of Study of the First Americans; Corvallis: Oregon State University Press, 1994.

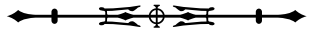


GRUHN, Ruth. Linguistic evidence in support of the coastal route of earliest entry into the New World. Man, London, v. 23, p. 77-100, Mar. 1988. DOI: https://doi.org/10.2307/2803034.

GUTHRIE, Robert D. Origin and causes of the Mammoth Steppe: a story of cloud cover, woolly mammals tooth pits, buckles, and insideout Beringia. Quaternary Science Review, Amsterdam, v. 20, n. 1, p. 549574, Jan. 2001. DOI: https://doi.org/10.1016/S0277-3791(00)00099-8.

HALL, Roberta L.; MCCARTHY, Donna; HALL, Don Alan. How were North American Sites of the Pleistocene-Holocene Transition Discovered? North American Archaeologist, Greensburg, v. 23, n. 2, p. 145-156, Apr. 2002. DOI: https://doi.org/10.2190/TJWCN86U-6FVY-TM2L.

HART, L. First Americans and the US National Park Service (NPS). In: KNUDSON, Ruthann; KEEL, Bennie C. (ed.). The Public Trust and The First Americans. Corvallis: Oregon State University Press; College Station: Center of Study of the First Americans, 1995. p. 3-6.

HAYNES Jr., C. Vance. Fluted projectile points: their age and dispersion. Science, Washington, v. 145, n. 3639, p. 1408-1413, Sept. 1964. DOI: https://doi.org/10.1126/science.145.3639.1408.

HAYNES, Gary; HUTSON, Jarod M. Clovis-era subsistence: regional variability, continental patterning. In: GRAF, Kelly; KETRON, Caroline V.; WATERS, Michael R. (ed.). Paleoamerican Odyssey. College Station: Texas A\&M University, 2013. p. 293-310.

HISCOCK, Peter. Occupying new lands: global migrations and cultural diversification with particular reference to Australia. In: GRAF, Kelly; KETRON, Caroline V.; WATERS, Michael R. (ed.). Paleoamerican Odyssey. College Station: Texas A\&M University, 2013. p. 3-11.

HOLEN, Steven R.; HOLEN, Kathleen. The Mammoth Steppe Hypothesis: the Middle Wisconsin (Oxygen Isotope Stage 3) peopling of North America. In: GRAF, Kelly; KETRON, Caroline V.; WATERS, Michael R. (ed.). Paleoamerican Odyssey. College Station: Texas A\&M University, 2013. p. 429-444.

HOLLIDAY, Vance T.; MILLER, Shane D. The Clovis Landscape. In: GRAF, Kelly; KETRON, Caroline V.; WATERS, Michael R. (ed.). Paleoamerican Odyssey. College Station: Texas A\&M University, 2013. p. 221-246.

HUBBE, Mark; NEVES, Walter A.; HARVATI, Katerina. Testing evolutionary and dispersion scenarios for the settlement of the New World. PLoS ONE, São Francisco, v. 5, n. 6, p. e11105, 2010. DOI: https://doi.org/10.1371/journal.pone.0011105.

HUTTERER, Karl L. Kennewick Man two decades later. PaleoAmerica, London, v. 1, n. 1, p. 4-6, Jan. 2015. DOI: https://doi.org/10.1179/2 $055556314 Z .0000000003$

IVES, John W:; FROESE, Duane; SUPERNANT, Kisha; YANICKI, Gabriel. Vectors, vestiges and Valhallas-Rethinking the corridor. In: GRAF, Kelly; KETRON, Caroline V.; WATERS, Michael R. (ed.). Paleoamerican Odyssey. College Station: Texas A\&M University, 2013. p. 149-170.
IZUHO, Masami. Human technological and behavioral adaptation lo landscape changes around the Last Glacial Maximum in Japan: a focus on Hokkaido. In: GRAF, Kelly; KETRON, Caroline V.; WATERS, Michael R. (ed.). Paleoamerican Odyssey. College Station: Texas A\&M University, 2013. p. 45-64.

JENKINS, Dennis L.; DAVIS, Loren G.; STAFFORD JR., Thomas W. CAMPOS, Paula F.; CONNOLLY, Thomas I:; SCOTT-CUMMINGS, Linda; HOFREITER, Michael; HOCKETT, Bryan; MCDONOUGH, Katelyn; LUTHE, lan; O'GRADY, Patrick W.; REINHARDT, Karl J.; SWISHER, Mark E.; WHITE, Frances; YATES, Bonnie; YOHE II, Robert M.; YOST, Chad; WILLERSLEV, Eske. Geochronology, archaeological context, and DNA at the Paisley Caves. In: GRAF, Kelly; KETRON, Caroline V.; WATERS, Michael R. (ed.). Paleoamerican Odyssey. College Station: Texas A\&M University, 2013. p. 485-510.

JOYCE, Daniel J. Pre-Clovis Megafauna Butchery sites in the western great lakes region, USA. In: GRAF, Kelly; KETRON, Caroline V.; WATERS, Michael R. (ed.). Paleoamerican Odyssey. College Station: Texas A\&M University, 2013. p. 467-484.

KELLY, Robert L. Maybe we do know when people first came to North America; and what does it mean if we do? Quaternary International, Amsterdam, v. 109/110, p. 133-145, 2003. DOI: https:// doi.org/10.1016/S1040-6182(02)00209-4.

KELLY, Robert L.; TODD, Lawrence C. Coming into the Country: early paleoindian hunting and mobility. American Antiquity, Cambridge, v. 53, n. 2, p. 231-244, Apr. 1988. DOI: https://doi.org/10.2307/281017.

KILBY, J. David; HUCKELL, Bruce B. Clovis Caches: current perspectives and future directions. In: GRAF, Kelly; KETRON, Caroline V.; WATERS, Michael R. (ed.). Paleoamerican Odyssey. College Station: Texas A\&M University, 2013. p. 257-272.

KNUDSON, Ruthann. The Public Trustand Archaeological Stewardship, In: KNUDSON, Ruthann; KEEL, Bennie C. (ed.). The Public Trust and The First Americans. Corvallis: Oregon State University Press; College Station: Center of Study of the First Americans, 1995. p. 9-28.

LANATA, José Luis; MARTINO, Luis; OSELLA, Ana; GARCIAHERBST, Arleen. Demographic conditions necessary to colonize new spaces: the case for early human dispersal in the Americas. World Archaeology, London, v. 40, n. 4, p. 520-537, Nov. 2008. DOI: https://doi.org/10.1080/00438240802452890.

LUCAS, Spencer G. Human footprints and the peopling of the Americas. PaleoAmerica, London, v. 3, n. 2, p. 97-100, Apr. 2017. DOI: https://doi.org/10.1080/20555563.2017.1306401.

LYNCH, Thomas F. Lack for evidence for glacial-age settlement of South America: replay to Dillehay and Collins and to Gruhn and Bryan. American Antiquity, Cambridge, v. 56, n. 3, p. 348-355, Apr. 1991. DOI: https://doi.org/10.2307/281424.

LYNCH, Thomas F. Glacial-age man in South America? A critical review. American Antiquity, Cambridge, v. 55, n. 1, p. 12-36, Jan. 1990. DOI: https://doi.org/10.2307/281490.

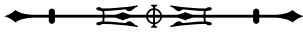


MACKIE, Quentin; DAVIS, Loren; FEDJE, Daryl; MCLAREN, Duncan; GUSICK, Amy. Locating Pleistoce-age submerged archaeological sites on the Northwest coast: current status of researche and future directions. In: GRAF, Kelly; KETRON, Caroline V.; WATERS, Michael R. (ed.). Paleoamerican Odyssey. College Station: Texas A\&M University, 2013. p. 133-148.

MARTIN, Paul S. The discovery of America. Science, Washington, v. 179, n. 4077, p. 969-974, Mar. 1973. DOI: https://doi.org/10.1126/ science.179.4077.969.

MELTZER, David J. The great Paleolithic war: how science forget an understanding of America's Ice Age past. Chicago: The University of Chicago Press, 2015.

MELTZER, David J. First peoples in a New World: colonizing Ice Age America. Berkeley: University of California Press, 2009.

MELTZER, David J.; GRAYSON, Donald K.; ARDILA, Gerardo; BARKER, Alex W.; DINCAUZE, Dena F; HAYNES, C. Vance; MENA, Francisco; NUÑEZ, Lautaro; STANFORD, Dennis J. On the Pleistocene antiquity of Monte Verde, Southern Chile. American Antiquity, Cambridge, v. 62, n. 4, p. 659-663, Oct. 1997. DOI: https:// doi.org/10.2307/281884.

MELTZER, David J.; ADOVASIO, James M.; DILLEHAY, Tom D. On a Pleistocene human occupation at Pedra Furada, Brazil. Antiquity, Cambridge, v. 68, n. 261, p. 695-714, Dec. 1994. DOI: https://doi. org/10.1017/S0003598X00047414.

MELTZER, David J. Why don't we know when the first people came to North America? American Antiquity, Cambridge, v. 54, n. 3, p. 471-490, July 1989. DOI: https://doi.org/10.2307/280776.

MILLER, Shane D.; HOLLIDAY, Vance T.; BRIGHT, Jordon. Clovis across the Continent. In: GRAF, Kelly; KETRON, Caroline V.; WATERS, Michael R. (ed.). Paleoamerican Odyssey. College Station: Texas A\&M University, 2013. p. 207-220.

MORROW, Juliet E.; GNECCO, Cristobal (ed.). Paleoindian Archaeology: a hemispheric perspective. Gainesville: University Press of Florida, 2006.

MORROW, Juliet E.; MORROW, Toby A. Geographic variation in fluted projectile points: a hemispheric perspective. American Antiquity, Cambridge, v. 64, n. 2, p. 215-230, Apr. 1999. DOI: https://doi. org/10.2307/2694275.

MORSE, Sarita Amy;; BENNETT, Matthew R.; GONZALEZ, Silvia; HUDDART, David. Techniques for verifying human footprints: reappraisal of pre-Clovis footprints in Central Mexico. Quaternary Science Reviews, Amsterdam, v. 29, n. 19/20, p. 2571-2578, Sept. 2010. DOI: https://doi.org/10.1016/J.quascirev.2010.03.012.

MOSIMANN, James E.; MARTIN, Paul S. Simulating overkill by Paleoindians: did man hunt the giant mammals of the New World to extinction? Mathematical models show that the hypothesis is feasible. American Scientist, Carolina do Norte,v.63,n.3,p.304-313, May/June 1975.
MOZART, Wolfgang, Amadeus. Réquiem em ré menor (K.626). Missa Católica Romana de encomenda dos mortos (Missa de Réquiem). 1971. Disponível em: https://pt.wikipedia.org/wiki/ Requiem_(Mozart)\#Letra. Acesso em: 22 abr. 2019.

MULLIGAN, Connie J.; KITCHEN, Andrew. Three-Stage Colonization Model for the peopling of the Americas. In: GRAF, Kelly; KETRON, Caroline V.; WATERS, Michael R. (ed.). Paleoamerican Odyssey. College Station: Texas A\&M University, 2013. p. 171-182.

NEVES, Walter A.; HUBBE, Mark; BERNARDO, Danilo; STRAUSS, André; ARAÚJO, Astolfo; KIPNIS, Renato. Early human occupation of Lagoa Santa, Eastern Central Brazil: craniometric variation of the initial settlers of South America. In: GRAF, Kelly; KETRON, Caroline V.; WATERS, Michael R. (ed.). Paleoamerican Odyssey. College Station: Texas A\&M University, 2013. p. 397-412.

NEVES, Walter A.; ZANINI, Maria do Carmo; MUNFORD, Danusa; PUCCIARELLI, Héctor Mário. O povoamento da América à luz da morfologia craniana. Revista USP, São Paulo, v. 34, p. 96-105, jun./ago. 1997. DOI: https://doi.org/10.11606/issn.23169036.v0i34p96-105.

O'BRIEN, Michael J.; LYMAN, R. Lee; SCHIFFER, Michael Brian. Archaeology as a Process: Processualism and its Progeny. Salt Lake City: The University of Utah Press, 2005.

O'ROURKE, Dennis H.; RAFF, Jennifer A. The Human Genetic History of the Americas: Review The Final Frontier. Current Biology, Cambridge, v. 20, n. 4, p. 202-207, Feb. 2010. DOI: https://doi.org/10.1016/j.cub.2009.11.051.

PITBLADO, Bonnie L. An argument for ethical, proactive, archaeologist-artifact collector collaboration. American Antiquity, Cambridge, v. 79, n. 3, p. 385-400, July 2014. DOI: https://doi. org/10.7183/0002-7316.79.3.385.

PITULKO, Vladimir; NIKOLSKIY, Pavel; BASILYAN, Aleksandr; PAVLOVA, Elena. Human habitation in Artic Western Beringia prior to the LGM. In: GRAF, Kelly; KETRON, Caroline V.; WATERS, Michael R. (ed.). Paleoamerican Odyssey. College Station: Texas A\&M University, 2013. p. 13-44.

POTTER, Ben A.; HOLMNES, Charles E.; YESNER, David R. Technology and economy among the earliest prehistoric foragers in interior Eastern Beringia. In: GRAF, Kelly; KETRON, Caroline V.; WATERS, Michael R. (ed.). Paleoamerican Odyssey. College Station: Texas A\&M University, 2013. p. 81-104.

PRASCIUNAS, Mary M. Mapping Clovis: projectile points, behavior and bias. American Antiquity, Cambridge, v. 76, n. 1, p. 107-126, Jan. 2011. DOI: https://doi.org/10.7183/0002-7316.76.1.107.

PRATES, Luciano; POLITIS, Gustavo; STEELE, James. Radiocarbon chronology of the early human occupation of Argentina. Quaternary International, Amsterdam, v. 301, p. 104-122, July 2013. DOI: https://doi.org/10.1016/j.quaint.2013.03.011.

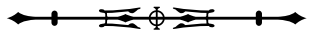


RAFF, Jennifer A.; BOLNICK, Deborah A. Does mitochondrial Haplogroup $X$ indicate ancient trans-atlantic migration to the Americas? A critical Re-Evaluation. PaleoAmerica, London, v. 1, n. 4, p. 297-304, Nov. 2015. DOI: https://doi.org/10.1179/2055556 315Z.00000000040.

REQUIEM (Mozart). In: Wikipédia, a enciclopédia livre. Flórida: Wikimedia Foundation, 2019. Disponível em: https://pt.wikipedia. org/w/index. php?title $=$ Requiem (Mozart)\&oldid $=54069682$. Acesso em: 22 abr. 2019.

SAINT PIERRE, Michelle de. Antiquity of mtDNA lineage D1g from the southern cone of South America supports pre-Clovis migration. Quaternary International, Amsterdam, v. 444, p. 19-25, July 2017. Part B. DOI: https://doi.org/10.1016/j.quaint.2017.05.054.

SELLET, Frederic. Fallen Giants: the story of Paleoindian point types on the North American Great Plains. In: VIALOU, Denis (ed.). Peuplements et Préhistoire en Amériques. Paris: Comité des Travaux Historiques et Scientifiques, 2011. p. 97-105.

SMITH, Heather L.; RASIC, Jeffrey T.; GOEBEL, Ted. Biface traditions of northern Alaska and their role in the peopling of the Americas. In: GRAF, Kelly; KETRON, Caroline V.; WATERS, Michael R. (ed.). Paleoamerican Odyssey. College Station: Texas A\&M University, 2013. p. 105-124.

STRINGER, Chris. Lone Survivors: how we came to be the only humans on Earth. New York: Times Book: Henry Holt and Company, 2012

TRIGGER, Bruce G. Alternative archaeologies: nationalist, colonialist, imperialist. In: PREUCEL, Robert W.; HODDER, Ian (ed.). Contemporary Archaeology in Theory: a reader. Oxford: Blackwell Publishers, 1996. p. 615-631.
WAGUESPACK, Nicole M. Pleistocene extinctions: the state of evidence and the structure of debate. In: GRAF, Kelly; KETRON, Caroline V.; WATERS, Michael R. (ed.). Paleoamerican Odyssey. College Station: Texas A\&M University, 2013. p. 311-320.

WATERS, Michael R.; STAFFORD JR., Thomas W. The First Americans: a review of the evidence for the Late-Pleistocene Peopling of the Americas. In: GRAF, Kelly; KETRON, Caroline V.; WATERS, Michael R. (ed.). Paleoamerican Odyssey. College Station: Texas A\&M University, 2013. p. 541-560.

WATERS, Michael R.; STAFFORD JR., Thomas W. Redefining the Age of Clovis: Implications for the Peopling of the Americas. Science, Washington, v. 315, n. 5815, p. 1122-1126, Feb. 2007. DOI: https://doi.org/10.1126/science.1137166.

WATSON, Patty J. Federal US Funding: First Americans Research. In: KNUDSON, Ruthann; KEEL, Bennie C. (ed.). The Public Trust and The First Americans. Corvallis: Oregon State University Press; College Station: Center of Study of the First Americans, 1995. p. 160-166.

WHEAT, Amber D. Survey of professional opinions regarding the peopling of the Américas. The SAA Archaeological Record, Washington, v. 12, n. 2, p. 10-14, Mar. 2012.

YELLEN, John E.; GREENE, Mary W. Archaeology and National Science Foundation. American Antiquity, Cambridge, v. 50, n. 2, p. 332-341, Apr. 1985. DOI: https://doi.org/10.2307/280491.

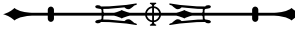

